\title{
Circular-Axial Representation of Human Evolution and Development in the Integral Theory: Educational Implications
}

\author{
Josep Gallifa $^{1}$ \\ ${ }^{1}$ FPCEE Blanquerna, Ramon Llull University, Barcelona, Spain \\ Correspondence: Josep Gallifa, FPCEE Blanquerna, Ramon Llull University, Barcelona, Spain.
}

Received: March 25, 2019

Accepted: April 10, 2019

Online Published: April 15, 2019

doi:10.20849/jed.v3i1.561

URL: https://doi.org/10.20849/jed.v3i1.561

\begin{abstract}
Integral Theory has become a common framework in different contexts to integrate the diverse consciousness manifestations. The wide use and discussion of this meta-theory in the most varied fields encourage the possibility of proposing enhancements in their conceptualization. This paper presents, for instance, a complementary aspect, which is an alternative way of representation: the circular-axial. The article discusses why this new way of representation is appropriate to the meta-theoretical concepts and why it has some advantages compared to the more popular representation of the four quadrants. Although compatible with the traditional representation, we argue that it fits better with other concomitant theories, and at the same time is equally explicative of the Integral Theory basics. Once described in detail, the new way of representation helps in the clarification of the different manifestations of consciousness as they are explained by the holonic theory. This development provides new intuitions to holistic/integral educational approaches addressed to human evolution and development. Finally, it is useful to characterize their corresponding educational roles.
\end{abstract}

Keywords: integral theory, representation, evolution and development, educational roles, consciousness

\section{Introduction}

\subsection{Integral Theory}

Kenneth E. Wilber $(2001,2005,2007)$ elaborated a meta-theory intended to explain all the knowledge coming from diverse sources and epochs, together with all the scopes of the human experience: The Integral Theory (IT). The purpose from the beginning of the 70s was to integrate Science, Psychology, Philosophy, and Spirituality. The development of the theory continued until today when it has been well known and widely discussed in academic and intellectual circles. The objective of IT is to provide a balanced, inclusive and comprehensive framework to define comprehensiveness and integrality, with the possibility of application of this framework to any scientific, professional or personal approach. Counting with a comprehensive approach allows the possibility of informing any area in order to refine their methods, contrast the validity of their claims and provide elements for their practical applications (Helfrich, 2008). The Wilber's model has been considered an integral theory of consciousness (Wilber, 1997b, 2000) with evolutional/developmental basis (Wilber, 1979).

This attempt to present an Integral Theory has some precursors that influenced Wilber as Henry Bergson, Teilhard de Chardin, Sri Aurobindo or Alfred North Whitehead. Teilhard de Chardin, for example, provided an evolutionary view of humanity that accounts for the physical, biological and cultural dimensions (Teilhard de Chardin, 2002), integrating science and religion.

The early works of Wilber led him to incorporate evolutionary ideas into the mind, the phylogenesis into the ontogenesis. In The Spectrum of Consciousness (Wilber, 1993) and No Boundary (Wilber, 2001c), he wanted to integrate the subjective knowledge and experience that comes from religious or spiritual traditions (which he referred as pre-modern) in the scientific and objective knowledge. For this purpose, he proposed the existence of a spectrum of human consciousness, where he included matter, body, mind, soul, and spirit. He integrated the pre-personal (id) and personal (ego) tensions that Freud described, with Buddhist spiritualties that emphasize the relationship between the personal arena (ego) and the transpersonal dimension (spirit). He, therefore, integrated East and West into a single spectrum in which he initially traced four levels of evolution: Egoic, Existential, Transpersonal, and Unity of Consciousness. Wilber became one of the reference transpersonal theorists of the late 70s (Helfrich, 2008) integrating Eastern and Western traditions in a single spectrum. 
At the beginning of the 80s, Wilber distanced from himself -in The Atman Project (1996b), Up from Eden (1996) and A Sociable God (2005b)-, as Helfrich (2008) explained, by discarding psychologies that consider transpersonal stages as a regression to infantile stages instead of understanding that human development is directed towards a new transpersonal stage. Wilber refined the four stages in 17 and compared them progressively with other maps of development: Aurobindo (cognition), Piaget (cognition), Commons and Richards (postformal thought), Kohlberg (moral), Graves (values), Erikson (psychosocial), Maslow (needs), Kagan (orders of consciousness), Loevinger (ego levels), Cook-Greuter (self-identity), Vedanta Yoga (koshas), Vajrayana Buddhism (kayas), Kabbalah (kingdoms), etc., assimilating hundreds of different maps predominantly in the context of the individual's subjective interior (Helfrich, 2008). Wilber with Engler and Brown (1986) revised his conception of the levels and redefined them as the ten points of support ("fulcrums") for the development of consciousness, making the specific correspondence of each level with the corresponding pathology patterns (Wilber, Engler \& Brown, 1986, p. 125).

In that model the basic structures are relatively stable patterns and, in contrast, the plural transitional lines are stage-specific, i.e. one level completely replaces the next. For example, in the Kohlberg's stages of moral development (pre-conventional, conventional and post-conventional) each stage is totally replaced with the new acquisition. In parallel in order to provide and refine the model for understanding the subject, Wilber undertook the task of including a model to comprehend the culture, an essential element for an integral model of the human evolution. For this, he designed the "We", expanding the subjective "I" and the objective "It". With this intersubjective dimension, he incorporated the characteristics of the postmodern way of thinking, characterized by relativism, organicism, and contextualism (Botella \& Gallifa, 1995). Effectively, in Up from Eden (1996) and A Sociable God (2005b) projected the subject in the collective dimension of the cultural development: From ontogenesis to the interior of phylogenesis. This three-dimensional perspective ("I", "We", "It") explains the triarchic nature of many formulations, as summarized in the following table:

Table 1. Correspondences with the Wilber's dimensions "I", "We", and "It"

\begin{tabular}{llll}
\hline & "I" & "We" & "It" \\
\hline $\begin{array}{l}\text { Max Weber: Three } \\
\text { spheres of value }\end{array}$ & Art & Moral & Science \\
\hline Plato & Beauty & Goodness & Truth \\
\hline $\begin{array}{l}\text { Karl Popper: three } \\
\text { worlds }\end{array}$ & Subjective & Cultural & Objective \\
\hline $\begin{array}{l}\text { Jürgen Habermas: three } \\
\text { areas of affirmations }\end{array}$ & $\begin{array}{l}\text { Subjective } \\
\text { sincerity }\end{array}$ & Inter-subjective/social justice & Objective truth \\
\hline Immanuel Kant & $\begin{array}{l}\text { Critique of } \\
\text { judgment/ } \\
\text { aesthetics }\end{array}$ & $\begin{array}{l}\text { Critique of practical/moral } \\
\text { reason }\end{array}$ & $\begin{array}{l}\text { Critique of pure } \\
\text { reason/Objective } \\
\text { science }\end{array}$ \\
\hline
\end{tabular}

Table elaborated from Wilber (1998), The marriage of sense and soul, pp.74-75.

Confronted with the creation of knowledge about consciousness, and to refine his epistemology, he proposed, with ideas drawn from Christian mysticism, the use of the three senses or "eyes" (Wilber, 2001b): Somatic eye (mono-logical/sensitive/physical senses), eye of the mind (dialogical/intelligible/rational senses) and the eye of the spirit (trans-logical/transcendent/inner senses).

\subsection{Holonic Theory}

Wilber introduced the concept of holon that Koestler (1967) formulated. Feeling the need to present a comprehensive model and wondering how to represent all the holons in a single system, he developed a system for representing all the holons. He added to the "I", "We" and "It", the "Its", the interobjective world. He presented Ecology or the social dimension as examples of the "Its". From a trinity of areas, he moved to a quaternary model, presenting a comprehensive scheme in four quadrants, which was denominated AQAL ("all quadrants, all levels"). Wilber's Integral Theory is effectively also known as the "AQAL model" (Wilber, 2001, 2005 , 2007). The model, or meta-theory, consists in its simplest formulation in quadrants, levels, lines, states and 
types (Wilber, 2001, 2005; Helfrich 2008). Wilber proposed it as a theory that explains human consciousness and experience in a comprehensive way. The following table summarizes the four quadrants (Wilber, 2001, 2005, 2007), with examples of authors who focused specifically on each of them:

Table 2. Quadrants of the AQAL Model

\begin{tabular}{ll}
\hline Upper-Left (UL) "I" & Upper-Right (UR) "It" \\
Interior Individual & Exterior Individual \\
Intentional, e.g. Freud & Behavioral e.g. Skinner \\
\hline Lower-Left (LL) "We" & Lower-Right (LR) "Its" \\
Interior Collective & Exterior Collective \\
Cultural, e.g. Gadamer & Social, e.g. Marx \\
\hline
\end{tabular}

With that development, Wilber $(2001,2005,2007)$ integrated modern and postmodern worldviews to the premodern one. The Wilber model considers, therefore, four dimensions in any consciousness act: subjective, objective, intersubjective (cultural) and interobjective (social) (Helfrich, 2008, p. 6). The quadrants thus cover all areas and perspectives of consciousness. In fact, Wilber speaks of units of consciousness that are in each of the quadrants (the "holons"), which are characterized by being both part and whole (Helfrich, 2008). Wilber's meta-theory unites the thought and wisdom of East and West and the acquisitions of the pre-modern, modern and postmodern worlds into a single system (Helfrich, 2008).

Wilber used the holonic theory to propose a post-metaphysics to understand reality as a manifestation of non-dual Spirit. In effect, Wilber's system proposes a minimal metaphysics at the moment of integrating evolution from the physiosphere, towards the biosphere and finally into the human noosphere (similarly to Teilhard de Chardin, 2002). If this evolution is pushed by the Eros/Will, there is another dimension, the result of the involution, that is to go back before the "Big Bang", which leads to the only one metaphysical assumption that Wilber contemplates: the "Agape" or genuine "Love" in the beginning. Except for this presupposition, research, says Wilber, should be as little influenced as possible by metaphysical elements (Helfrich, 2008).

\subsection{Use of the Integral Theory in Diverse Fields}

The Wilber's Integral Theory is widely used in different fields and approaches: Beck and Cowan (2005) in the V-Memes of a culture, Esbjörn-Hargens (2005) or Murray (2009) in Integral Education, Laloux (2014) in the evolution of organizations, Thomas (2018) in Integral Leadership, among many others. More than 60 fields have been reframed using Integral Theory. Recently this approach has gained acceptance in academic forums and communities.

The Integral Theory could be useful for scientific exploration in multiple and diverse kinds of studies: Scientific exploration of contemporary anomalies "needs an objective interdisciplinary forum for comfortable professional discussion of the phenomena and their implications" (Jahn, 1989). The Integral Theory could be this forum. "The scientific account of a person's consciousness and its relation to her brain" (Smythies, 2009) could be also represented as the relationship between the subjective-objective dimensions in the Integral Theory. In addition the multidimensionality of Integral Theory could serve "to encompass all subjective, intuitive, impressionistic, or aesthetic aspects of a scientific situation which, while not submitting comfortably to prevailing catalogs and formalisms, nonetheless are found empirically, or hypothesized heuristically, to be relevant to the given event or process" (Jahn, 1989). Besides that, the relationship between consciousness phenomena and their impact in socio/cultural/political events (Orme-Johnson \& Oates, 2009) could be studied as a relationship between the subjective and intersubjective dimensions of the Integral Theory. These previous possibilities are only some examples of scientific exploratory studies that would benefit from having a common framework such as the one represented by the Integral Theory.

A theoretical framework evolves by criticism and rationality, in forums of discussion and debate. In that sense, some recent contributions to amplify the IT are: On one hand, the delving in the interobjective quadrant (Gallifa, 2018), understood also as the field for human collective transformational knowledge and the use of human will and abilities to create artifacts. On the other hand the definition of integral thinking (Gallifa, 2018e) as the thinking appropriate to the holistic consciousness, which is necessary to relate a single part of the reality with the whole holarchy of the AQAL model. 
This paper is another complementary attempt to modestly contribute to the enhancement of Integral Theory. It explores a different way of representing Integral Theory, an alternative way to the more popular model of quadrants. Although quadrants seem to be very fundamental in the model (AQAL), this paper will argue why they are not so crucial. This will be demonstrated with the proposal of a new format of representation and with the arguments about why this new proposed format is equally appropriate to the Integral Theory.

\section{A New Format for Representing Integral Theory (IT)}

\subsection{Generalities}

Coordinate axes are a general way for representing directionality in the four directions of the plane and can be used to define measurements of progress in each one of the dimensions. On the other hand, a circle is a representation of wholeness. Evolution and wholeness are two characterizing traits of IT.

The proposal for an appropriate new format of representation is quite simple and intuitive: To use coordinate axes instead of quadrants, and circles to represent the horizontal correspondences. The advantages are that the axes can represent better linear evolution, stages, and deepness, than quadrants. These concepts are crucial in Wilber's IT. Circles can represent better horizontal correspondences and the span of the model. These two traits deepness and span characterize Wilber's model, which is founded in the whole holarchy (holarchy and heterarchy) and in the proprieties of the holons (Helfrich, 2007, 2008).

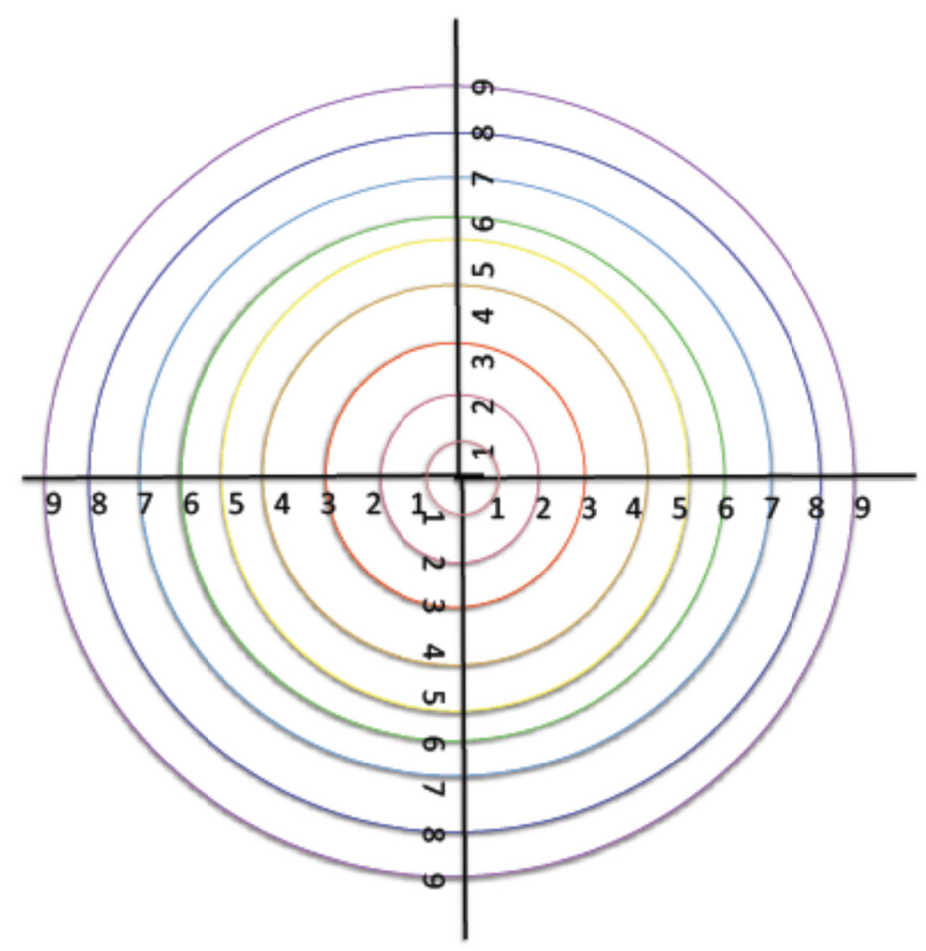

Figure 1

\subsection{Evolution and Development in Each Axis}

In each dimension, two concepts can be represented: evolution and development. Evolution is the integrative part, defined with "fulcrums" (Wilber et al., 1986), or steps like in a ladder. The 'climber' can go up and down. At the laterals, in each one of the directions, there can be represented developmental lines, which are fixed, time-related and stage-dependent evolutional acquisitions.

Next, we'll represent a summarized exploration for each dimension. We'll expand developmental lines in each one of the quadrants (Wilber developed them only in the subjective dimension). We'll represent eight lines in each dimension but the number can be higher.

Objective. In the Wilber model, the objective quadrant contains the natural 'objects'. Natural objects and phenomena are studied by the development of the diverse sciences. The different families of sciences are, 
therefore, the developmental lines in this dimension. The model may include as an extension the "objective" social/human sciences. The integrative dimension includes the rationale of the evolution of the sciences as Kuhn (1970) explained. They can be represented in a 'science-graph':

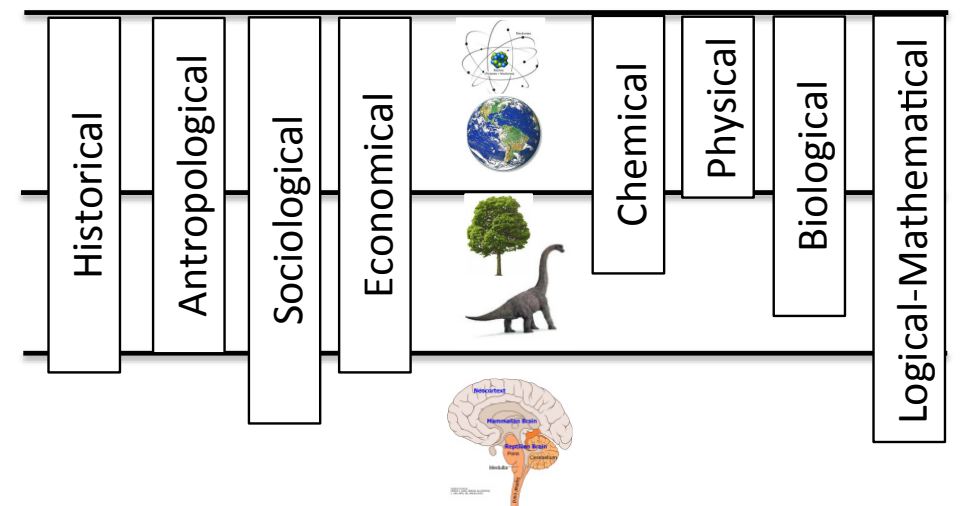

Figure 2

Subjective. The evolution of the self-system of the consciousness integrates the subjective evolution, as Wilber explained. Developmental lines are the development of multiple capacities, for example, the multiple intelligences of Gardner $(2003,2016)$. These lines have evidence-based research. The psychograph can be represented as follows:

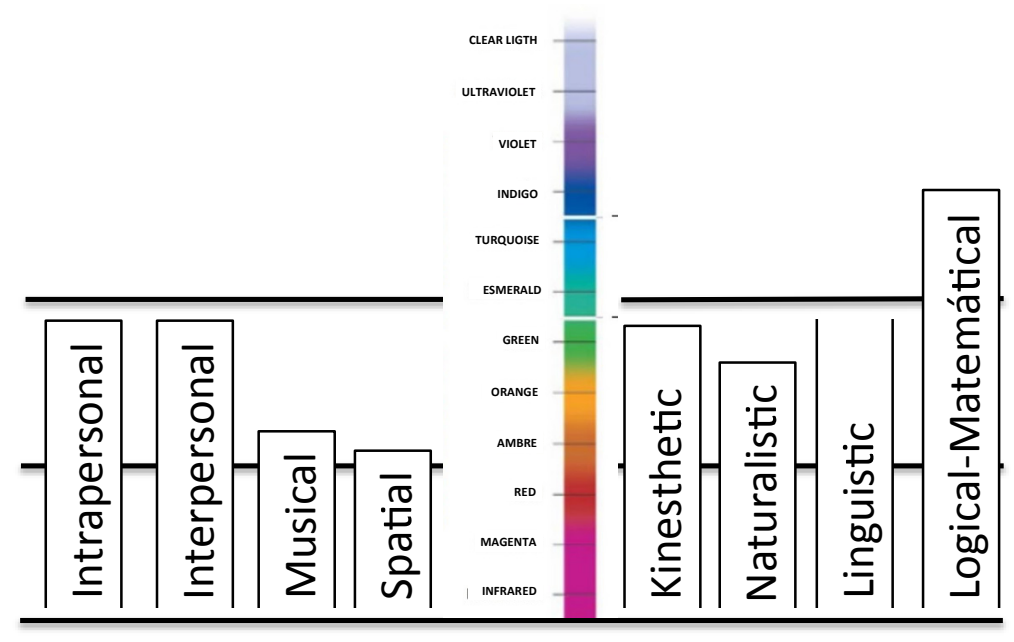

Figure 3

Intersubjective. The intersubjective evolution can be represented as a spiral, like the Spiral Dynamics model for the evolution of V-memes or worldviews in a culture (Beck \& Cowan, 2005). The societal developments are the lateral developmental lines. They have also an intersubjective representational character (Gallifa 2018), following Harari (2014) views. 


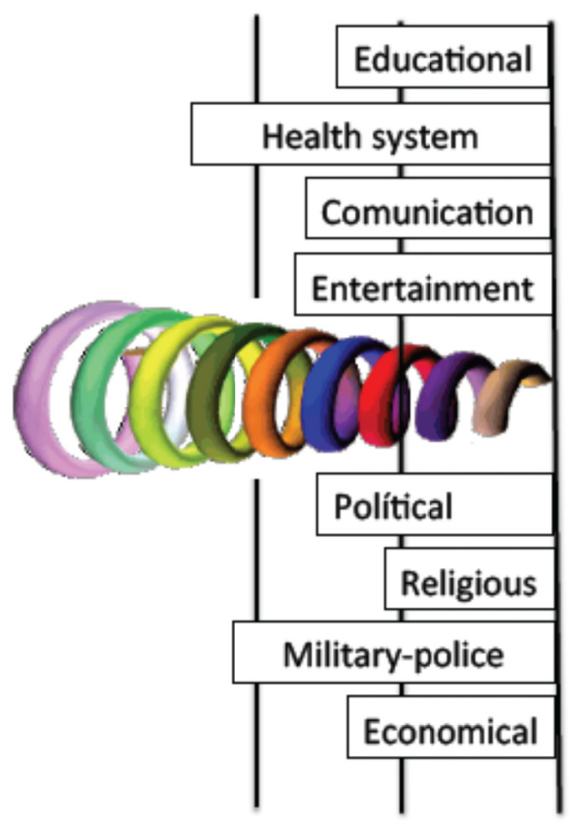

Figure 4

Interobjective. The interobjective dimension includes the artifacts produced by the technical evolution of humanity. The integration of this dimension is the process of evolution of the tekhnes or ars. The developmental lines are the different families of tekhnes (Gallifa, 2018), also included in the Wilber model in the interobjective quadrant.

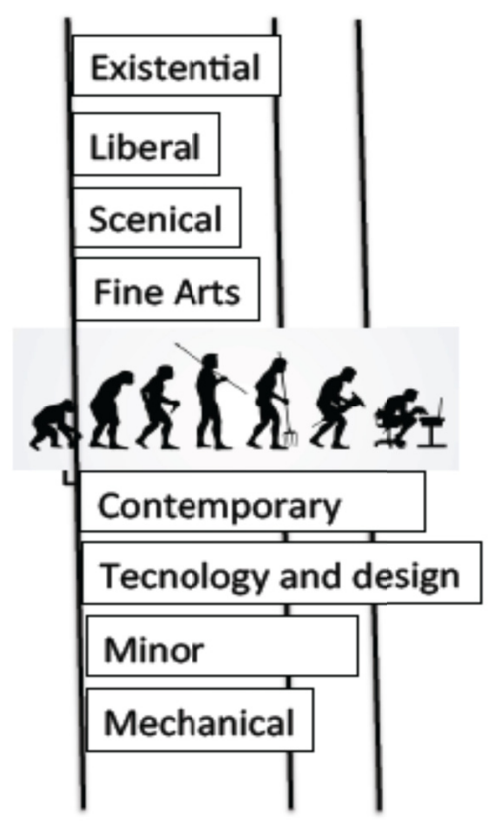

Figure 5

Although in our approach we proposed a small difference with the amplification respect Wilber's interobjective quadrant, the same representation can be used with the strict Wilberian approach. 
2.3 An Integrated Summary of the Partial Representations, Towards a Joined Representation of the Integral Theory

Until now we have been considering the following elements in each one of the human evolution directions:

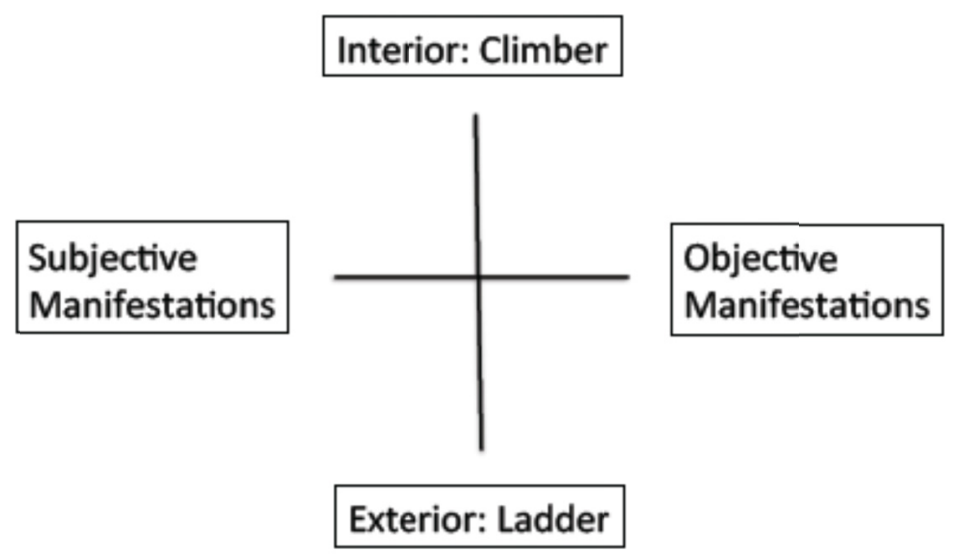

Figure 6

A table summarizes the four dimensions of IT:

Table 3. Evolution and development in Integral Theory

\begin{tabular}{|c|c|c|c|c|}
\hline \multirow[t]{2}{*}{$\begin{array}{l}\text { Dimensions of } \\
\text { Integral Theory:\# }\end{array}$} & \multicolumn{2}{|l|}{$\begin{array}{l}\text { Integration } \\
\text { (Evolution): }\end{array}$} & \multicolumn{2}{|l|}{$\begin{array}{l}\text { Differentiation } \\
\text { (Development): }\end{array}$} \\
\hline & $\begin{array}{l}\text { Exterior } \\
\text { (Ladder) }\end{array}$ & $\begin{array}{l}\text { Interior } \\
\text { (Climber) }\end{array}$ & $\begin{array}{l}\text { Objective } \\
\text { manifestations }\end{array}$ & $\begin{array}{l}\text { Subjective } \\
\text { manifestations }\end{array}$ \\
\hline $\begin{array}{l}\text { Objective } \\
\text { 'It' } \\
\text { (I)\# }\end{array}$ & $\begin{array}{l}\text { Evolutional line } \\
\text { (Physiosphere, } \\
\text { Biosphere, brain) }\end{array}$ & $\begin{array}{l}\text { Evolution of the } \\
\text { diverse sciences }\end{array}$ & Sciences of Nature & $\begin{array}{l}\text { Human and Social } \\
\text { Sciences }\end{array}$ \\
\hline $\begin{array}{l}\text { Interobjective } \\
\text { 'Its' } \\
\text { (A)\# }\end{array}$ & $\begin{array}{l}\text { Evolution of } \\
\text { knowledge in a } \\
\text { tekhne }\end{array}$ & $\begin{array}{l}\text { Process of learning in } \\
\text { a tekhne }\end{array}$ & Objective tekhnes & Subjective tekhnes \\
\hline $\begin{array}{l}\text { Intersubjective 'We' } \\
\text { (C)\# }\end{array}$ & Spiral Dynamics & $\begin{array}{l}\text { Evolution of the } \\
\text { human cultures and } \\
\text { societies }\end{array}$ & Objective institutions & Subjective institutions \\
\hline $\begin{array}{l}\text { Subjective } \\
\text { 'I' } \\
\text { (T)\# }\end{array}$ & $\begin{array}{l}\text { Spectrum of the } \\
\text { consciousness }\end{array}$ & $\begin{array}{l}\text { Evolution of the } \\
\text { consciousness }\end{array}$ & $\begin{array}{l}\text { Multiple intelligences, } \\
\text { objective }\end{array}$ & $\begin{array}{l}\text { Multiple intelligences, } \\
\text { subjective }\end{array}$ \\
\hline
\end{tabular}

(Adapted from Gallifa, 2019)

A holonic representation of the units in each one of the four dimensions is: 
Table 4. Basic unities in IT

\begin{tabular}{|c|c|c|}
\hline \multirow{2}{*}{$\begin{array}{l}\text { Dimensions of the Integral } \\
\text { Theory: }\end{array}$} & \multicolumn{2}{|l|}{ Basic unities: } \\
\hline & Exterior & Interior \\
\hline Objective & Objects & Objective Knowledge \\
\hline ' It' & Phenomena & \\
\hline \multicolumn{3}{|l|}{ (I) } \\
\hline Interobjective & Artifacts & Abilities \\
\hline 'Its' & & Systems \\
\hline \multicolumn{3}{|l|}{ (A) } \\
\hline Intersubjective & V-Memes & Organizational cultures \\
\hline 'We' & Worldviews & Social consciousness \\
\hline \multicolumn{3}{|l|}{ (C) } \\
\hline Subjective & Mental "images" & Levels of desire \\
\hline 'I' & Subjective holons & Individual consciousness \\
\hline$(\mathrm{T})$ & & \\
\hline
\end{tabular}

Summary of the collective representations in each axe and unities of evolution (Gallifa, 2019)

\subsection{Representation of the Integral Theory}

Without losing any of the traits and potentialities of IT, as was originally formulated by Wilber $(2001,2005$, 2007), we propose to represent alternatively the dimensions of the holarchy in coordinate axes, instead of quadrants: A vertical axis for subjective-objective worlds (top-down) and a horizontal axis for the intersubjective-interobjective worlds (left-right).

In the graph presented there are four directions, each one with a different kind of representation.

\section{Symbolic and personal}

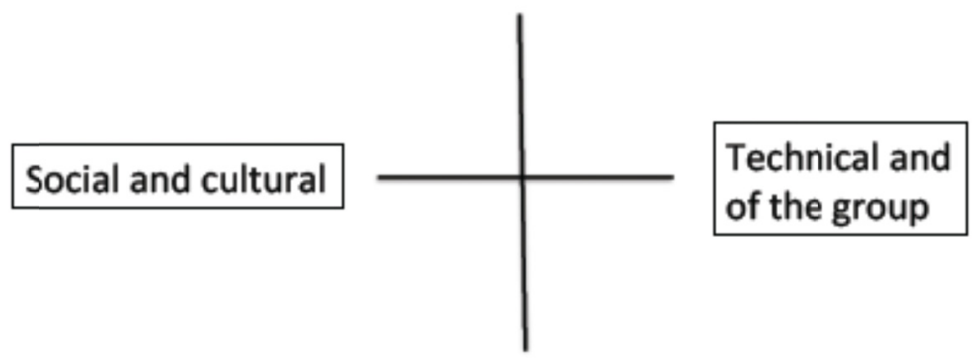

\section{Objective reality}

Figure 7

It can be established an equivalence with Wilber's quadrants: 


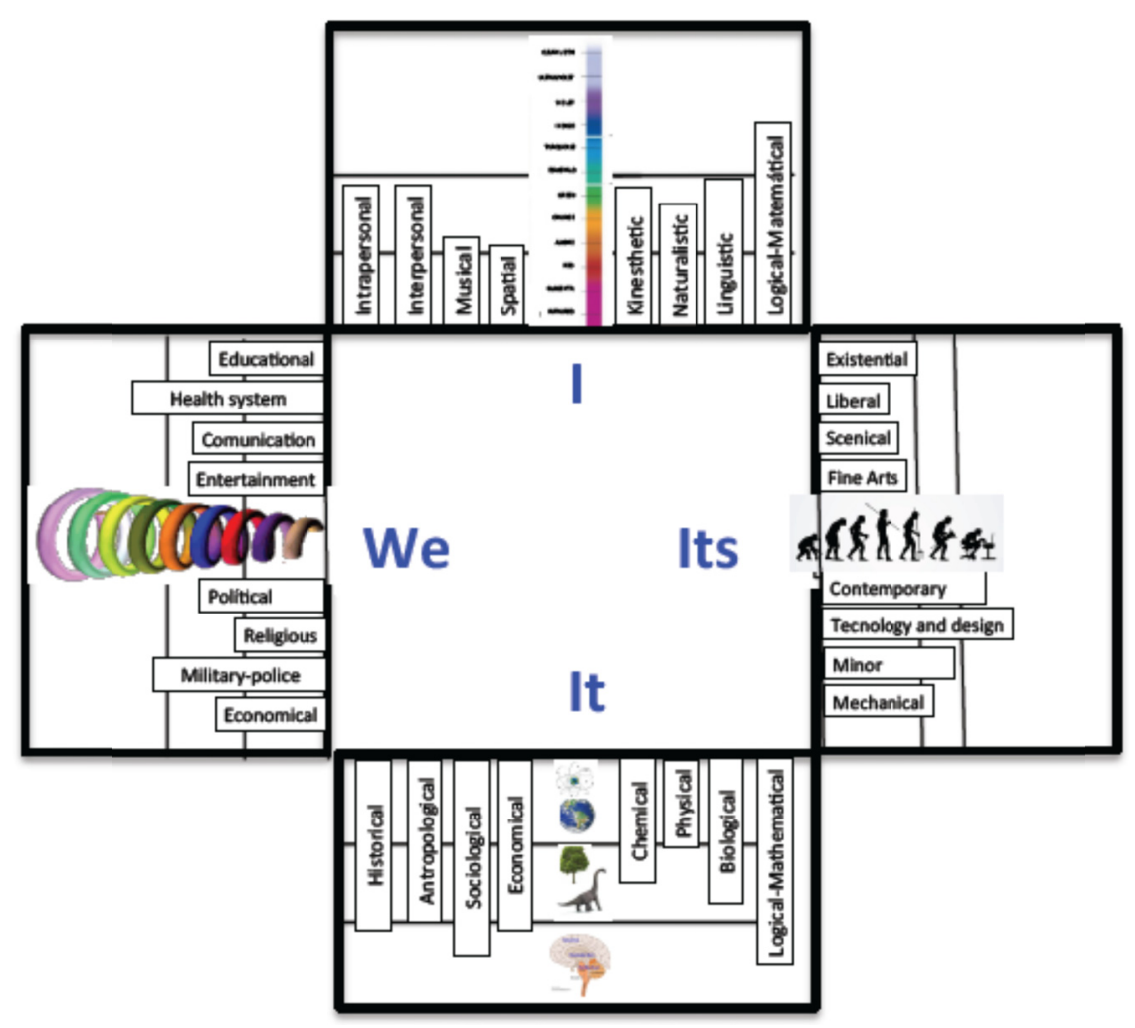

Figure 8

Representation of the quadrants of the holarchy in the model presented.

The levels of evolution can be represented in the following graph:

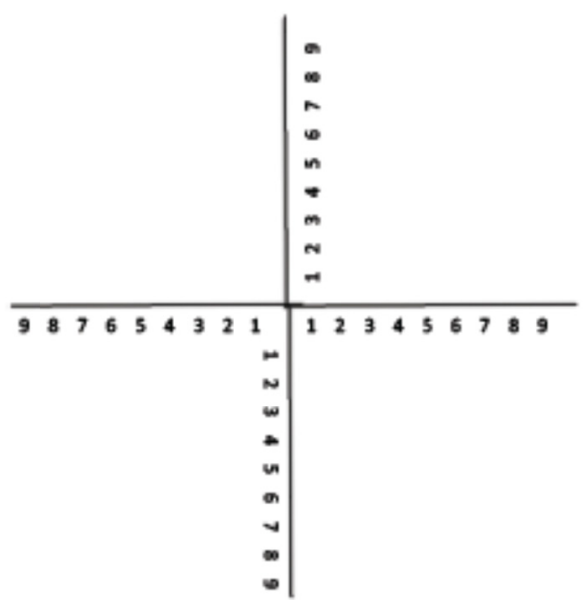

Figure 9

This reorganization changes the spatial distribution of Wilber. Each one of the four defined directions allows for representing a linear evolution in one direction (holonic depth). It can also be represented the horizontal correspondence (holonic amplitude). It's necessary to mention that the numbers throughout the paper have horizontal correspondence in coincidence with a color of the spectrum. In addition, the graph to represent the entire holarchy has the same structure than a holon, or more specifically: it's a holon, the holon formed by the entire holarchy or the representation of the Integral Theory of Wilber. 
The different types of holons can also be represented in this graph: simple (individual mental representations), composite (social, cultural or v-memes representations), artifacts (produced by an art -tekhne-, 'art-factum', made through an art), and neuronal structures (modules) of the human brain and their correspondence with the objects and phenomena of the 'objective' world.

The next figure is a representation of the integrality.

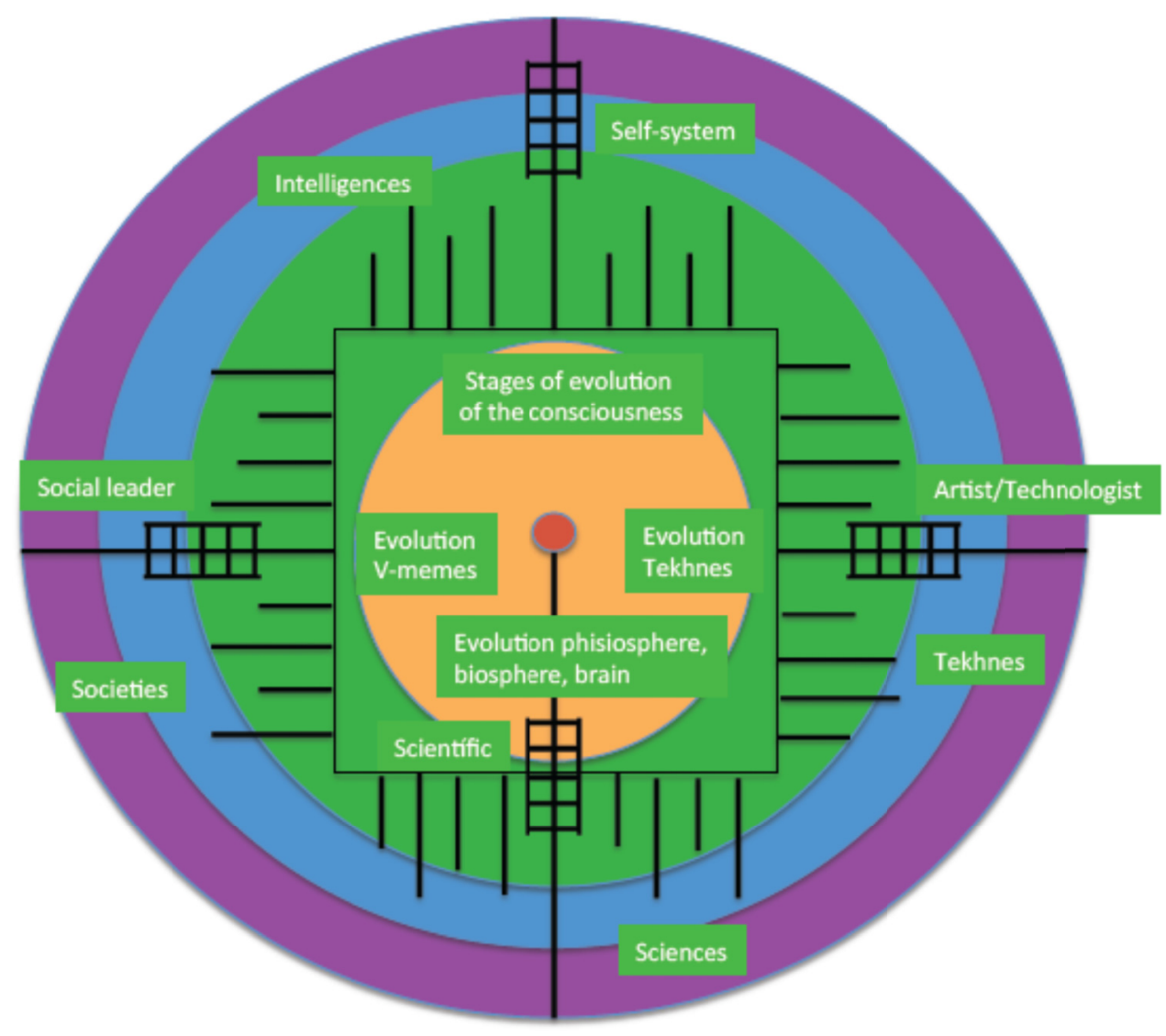

Figure 10

In this previous figure, it can be seen the whole holarchy in more detail. Starting from the central point, the evolution is represented, first of all in the physical and biological dimensions (objective dimension). This evolution continues in the noosphere in the four dimensions. In each axis there is the central integration, the evolution, where there is up and down movement, so we drew a ladder. The lines on both sides are the lines of development in each dimension. Normally these lines are stable, subjected to stages and to linear evolution, in the development process affected by space-time. In each dimension, there is the representation of depth: To more profundity more consciousness. And also the representation of amplitude: To more development of lateral lines more span.

As far as the lateral correspondence between levels is concerned, we present the following table, which summarizes the whole evolution throughout the holarchy.

Table 5. Complete Holarchy

\begin{tabular}{lllll}
\hline & It. Behavioral & I & We & Its \\
& Intentional & Cultural/social & $\begin{array}{l}\text { Systemic/ } \\
\text { Organizational }\end{array}$ \\
\hline E1 & Atoms & Apprehension & Physic pleromatic & Galaxies \\
\hline
\end{tabular}




\begin{tabular}{|c|c|c|c|c|}
\hline E2 & Molecules & & & Planets \\
\hline E3 & Prokaryotic & Irritability & Protoplasmic & Gaia system \\
\hline E4 & Eukaryotic & & Vegetative & $\begin{array}{l}\text { Heterotrophic } \\
\text { ecosystems }\end{array}$ \\
\hline E5 & $\begin{array}{l}\text { Neuronal } \\
\text { organisms }\end{array}$ & Sensation & Locomotor & $\begin{array}{l}\text { Societies with division } \\
\text { of work }\end{array}$ \\
\hline E6 & Neural cord & Perception & & $\begin{array}{l}\text { Societies with division } \\
\text { of work }\end{array}$ \\
\hline E7 & Reptilian brain & Impulse & $\begin{array}{l}\text { Uroboric } \\
\text { (undifferentiation) }\end{array}$ & Groups/families \\
\hline $\mathrm{E} 8$ & Limbic sistem & Emotion & Typhonic & Groups/families \\
\hline 1 & $\begin{array}{l}\text { Neocortex (triune } \\
\text { brain) }\end{array}$ & $\begin{array}{l}\text { Symbols-representations } \\
\text { Instinctive self }\end{array}$ & $\begin{array}{l}\text { Survival sense } \\
\text { Archaic } \\
\text { Archaic vision } \\
\text { Clans of survival } \\
100,000 \mathrm{y} . \\
0-18 \mathrm{~m} .\end{array}$ & $\begin{array}{l}\text { Hunter and gatherer } \\
\text { Stone age } \\
\text { (homo habilis } 2,5 \\
\text { millions y.) } \\
\text { Lithic techniques } \\
\text { Fire ( } 300,000 \text { y.), } \\
\text { Tools revolution }\end{array}$ \\
\hline 2 & $\begin{array}{l}\text { Complex } \\
\text { Neocortex }\end{array}$ & $\begin{array}{l}\text { Concepts } \\
\text { Magic self }\end{array}$ & $\begin{array}{l}\text { Familiar spirits } \\
\text { Magic } \\
\text { Animist-magic } \\
\text { Tribal/villages } \\
\text { Ethnic tribes } \\
70.000 \text { y. Cognitive } \\
\text { revolution } \\
50,000 \text { y. } \\
1-3 \mathrm{y} .\end{array}$ & $\begin{array}{l}\text { Horticulture and } \\
\text { pastoralism. } \\
\text { Neolithic revolution } \\
(10,000-9,000 \text { y.) } \\
\text { Neolithic, polished stone } \\
\text { tools: } 10,000 \text { y., pottery } \\
\text { and weaves }(9,000 .) \text {. } \\
\text { Cooper Age }(8,000 \text { y.) } \\
\text { Agricultural techniques, } \\
\text { domestication }(11,000 \\
\text { y.: wheat, goats }) \\
\text { Primitive vulgar arts }\end{array}$ \\
\hline 3 & $\begin{array}{l}\text { Structure-function } \\
1\end{array}$ & $\begin{array}{l}\text { Rules- concrete } \\
\text { operations } \\
\text { Egocentric } \\
\text { Mythic }\end{array}$ & $\begin{array}{l}\text { Power gods } \\
\text { Empires }(7,000 \quad \text { years } \\
\text { Egypt }) \\
\text { Feudal Empires } \\
\text { Impulsive self } \\
\text { 10,000 y. } \\
3-6 \text { y. } \\
\text { Exploiter Empires } \\
\text { Mythic primal }\end{array}$ & $\begin{array}{l}\text { Scripture 5,500 y. } \\
\text { History beginning. } \\
\text { Bonze age }(4,000 \mathrm{y} .) \\
\text { Iron age }(3,200 \mathrm{y} .) \\
\text { Money }(5,000 \mathrm{y} .) \\
\text { Agrarian } \\
\text { Minor/major arts }\end{array}$ \\
\hline 4 & & & $\begin{array}{l}\text { Force of Truth } \\
\text { Mythic order } \\
\text { Mythic evolved } \\
\text { First nations, Polis }(2,500 \\
\text { y.) } \\
\text { Rule-role } \\
\text { Authoritarian }\end{array}$ & Major Arts \\
\hline
\end{tabular}




\begin{tabular}{|c|c|c|c|c|}
\hline & & & $\begin{array}{l}5,000 \mathrm{y} \\
7-8 \mathrm{y}\end{array}$ & \\
\hline 5 & $\begin{array}{l}\text { Structure-function } \\
2\end{array}$ & $\begin{array}{l}\text { Formal-operations } \\
\text { Formal } \\
\text { Achiever }\end{array}$ & $\begin{array}{l}\text { Progressive impulse } \\
\text { Rational } \\
\text { Scientific-rational. } \\
\text { Nation-state } \\
\text { Corporative states } \\
\text { Achiever } \\
\text { Capitalist democracies } \\
300 \text { y. } \\
9-14 \text { y. }\end{array}$ & $\begin{array}{l}\text { Print press } \\
\text { Scientific revolution } \\
(500 \mathrm{y} .) \\
\text { Industrial revolution } \\
\text { Steam machine } \\
\text { Technique } \\
\text { Design }\end{array}$ \\
\hline 6 & $\begin{array}{l}\text { Structure-function } \\
3\end{array}$ & $\begin{array}{l}\text { Vision-logic } \\
\text { (Pluralist } \\
\text { Meta-systemic) } \\
\text { Sensible }\end{array}$ & $\begin{array}{l}\text { Human bonding } \\
\text { Centauric } \\
\text { Pluralistic } \\
\text { Planetary } \\
\text { Personalist } \\
\text { Vicarious experience } \\
\text { (Graves) } \\
\text { Communities of } \\
\text { value/fluid organizations } \\
\text { Social democracy } \\
150 \mathrm{y} . \\
15-21 \mathrm{y} .\end{array}$ & $\begin{array}{l}\text { Revolution of } \\
\text { information } \\
\text { Arts of media and } \\
\text { communication } \\
\text { Social networks }\end{array}$ \\
\hline 7 & $\begin{array}{l}\text { Structure-function } \\
4\end{array}$ & $\begin{array}{l}\text { Post-formal } \\
\text { (Vision-logic } \\
\text { Paradigmatic) } \\
\text { Integral emergent }\end{array}$ & $\begin{array}{l}\text { Flexible flow } \\
\text { Systemic } \\
\text { Common integral } \\
50 \mathrm{y} \text {. } \\
\text { Centered in the world }\end{array}$ & $\begin{array}{l}\text { Existential arts } \\
\text { Integral theory }\end{array}$ \\
\hline 8 & & $\begin{array}{l}\text { Symbolic } \\
\text { (Vision logic } \\
\text { Inter-paradigmatic) } \\
\text { Integral mature }\end{array}$ & $\begin{array}{l}\text { Holistic vision } \\
\text { Holonic } \\
\text { Holistic meshwork } \\
30 \mathrm{y} . \\
\text { Existential Wholeness } \\
\text { Mind and spirit }\end{array}$ & $\begin{array}{l}\text { Technologies/ } \\
\text { Existential arts } \\
\text { Artificial intelligence }\end{array}$ \\
\hline
\end{tabular}

Adaptation from Wilber (1995). A brief history of everything, p. 74; and from Wilber (2005) What Is Integral Spirituality? (first draft, June 2005) p. 5., with some author's enhancements (Gallifa, 2018).

\subsection{Characterization of the Integrality}

The new representation helps in understanding better the integrality. A particular approach, in whatever field, is integral if it has comprehensiveness, coherence, completeness, and balance, which should be expressed in the following four concepts (Gallifa, 2019):

- Amplitude in the different developmental lines (span)

- Evolutionary depth, especially in subjective dimensions: More depth means more consciousness.

- Multidimensionality: Consideration of the four directions.

- Elevation: Depth in the four dimensions, elevation to the second tier of consciousness (holistic consciousness, integral thinking). 
These points represent the integrality. When only there is the first one, an approach is usually considered integral but more appropriately would be "pseudo-integral" (amplitude without depth). The presence of these four points defines integrality, going from less to more. The last point includes the previous ones and is necessary for a fully integral approach (progress towards stages of the second tier of holistic/integral consciousness).

\section{Advantages of the Circular-Axial Representation}

The circular-axial representation presented is an excellent way for representing the IT, equivalent to the representation using quadrants. In some aspects, the proposed representation enhances the quadrants-based one. We present different arguments to support this claim:

1). The circular-axial way has a better correspondence with the holonic theory. The holonic theory supports IT ontology. With the new representation, the IT is itself a holon, inclusive of all holons, with the same holonic structure. I: Objective, A: interobjective, C: intersubjective, T: subjective. Because the IT holon is more elevated and inclusive, provides telos to the holons of the contained holarchy. The representation is more coherent and clarifies the ontological nature of IT.

2). The new representation allocates better the holons in the holarchy. There is the possibility of allocating a holon in a quadrant (as the Wilber model proposes), but also understand a holon as a fractal of the whole holarchy, with the same form, using the integral thinking (Gallifa, 2018d, 2018e, 2019).

$3)$. The graphical representation of the holarchy in axes and circles seems more appropriate to the vertical relations (holarchy) and horizontal ones (heterarchy): The hierarchy in the axes or directions of space and the heterarchy in form of lateral correspondences in circles. This representation expresses better the model that represents.

4). The new model has better adequacy to universal metaphysical representations. Linear evolution and circular span are universal metaphysic representations of the infinite world (circular or spherical) and the world of the Kav (linear), in the Jewish Kabbalah for example.

5). The new representation has a mandala-like form. A mandala is an internal-external form that has the trait that when the evolution goes throughout the lines to the exterior is approaching at the same time to the interior, the center of the mandala. It represents the involution (going to the central point) and the evolution (going to the exterior). On the other hand, axes in the four dimensions are the simplest representation of a tree. Used in different times and cultures mandalas and trees are the symbols to represent complexity.

6). The new representation clarifies better the distinction between evolution and development. Evolution is the central line in each dimension, more flexible in the stages, that integrates the evolutionary steps, like a ladder. The climber can go up or down. On the contrary developmental lines are more fixed, stage created, where stages are fixed and resistant acquisitions. A new stage goes ahead of the previous one. Evolution and development in the different IT dimensions is a concretion that is implicit in Wilber's representation but not so adequately represented.

7). Epistemological correspondence. There is a better representation of the correspondence with epistemologies. As Wilber explained, and other works concreted (Gallifa, 2018b, 2018c), a correspondence between ontologies, epistemologies, and methodologies it's a necessary point to integrate research findings.

Table 6. Paradigms or research traditions: Adaptation from Gallifa (2018b, 2018c)

\begin{tabular}{lllll}
\hline Paradigms: & $\begin{array}{l}\text { Logic Empirical } \\
\text { Science }\end{array}$ & Constructivism & $\begin{array}{l}\text { Conceptualism or } \\
\text { Productive } \\
\text { Science }\end{array}$ & Phenomenology \\
\hline Epistemology & $\begin{array}{l}\text { Episteme } \\
\text { theoretike }\end{array}$ & $\begin{array}{l}\text { Episteme praktike, } \\
\text { phronesis }\end{array}$ & $\begin{array}{l}\text { Episteme poietike, } \\
\text { tekhne }\end{array}$ & Nous \\
\hline Ontology & Realism. & $\begin{array}{l}\text { Reality constructed } \\
\text { by the subject. } \\
\text { Oechanicism }\end{array}$ & $\begin{array}{l}\text { Creationism } \\
\text { artist-artifact. } \\
\text { Outhority within a } \\
\text { tradition }\end{array}$ & $\begin{array}{l}\text { Essence and } \\
\text { intentionality of } \\
\text { consciousness. }\end{array}$ \\
& & & $\begin{array}{l}\text { Holism and } \\
\text { integralism }\end{array}$ \\
\hline Methodology & Experimental & Hermeneutical and & Conceptualist and & $\begin{array}{l}\text { Phenomenological } \\
\text { and Structuralist }\end{array}$ \\
& & Anthropological & Design-Based & \\
& & & &
\end{tabular}


8). It's a better representation of the holistic consciousness. The development made helps in the representation of the holistic consciousness, because joins in a single schema a model for a consciousness act. It is a good basement for integral thinking and for the evolution of the consciousness to the second tier (Graves, 1974; Wilber, 1993; Beck \& Cowan, 2005)

9). Correspondence with other systems. Vertical axis reproduces the "scale" of being or the "great chain" of being, in correspondence with Middle Age developments. Additionally, horizontal correspondence represents the polarities feminine-masculine, right hemisphere-left hemisphere. The theory can be represented also as an intuitive correspondence with personality styles as an inverted Enneagram. These are some among the meaningful intuitive correspondences with other theories and models.

10). The new representation is intuitive, natural, and practical. Once familiar with it, the representation is easy and equivalent to one of the quadrants.

\subsection{Contribution to the Meta-Problem of Consciousness}

The former representation can provide some insights into the denominated meta-problem of consciousness. The meta-problem of consciousness consists in answering the question of why there is the 'hard problem' of consciousness, which means understanding the path from the physical domain to consciousness (Chalmers, 2018).

We can provide some tentative answer. From the presented developments we can observe:

- There is a hard problem because consciousness is at the same time different things implicating different cerebral areas and mechanisms. Each dimension is a kind of consciousness.

- There is, therefore, a plurality of hard problems. Identifying the hard problem as a single problem makes probably the problem harder, and perhaps irresoluble.

- From this point of view, to approach the hard problem, first of all, there is a need for classifying the different phenomena that can be denominated as consciousness. One way to do so is the classification of holons, as IT does. The model provided clarifies the advance in that classification.

- Then in each kind of phenomena, there is a special hard problem of understanding the relationship between cerebral areas and the particular consciousness levels and dimensions.

\section{Implications for Educational Practice}

\subsection{Four Logics for Holistic Education and for Integral Education}

The circular-axial representation clarifies the evolutionary and developmental lines in each one of the four dimensions of the Integral Theory. This refinement has the potentiality to develop practical educational implications.

In recent research, Gallifa (2018d) characterized holistic education as a result of a process of typifying and applying a holistic consciousness act. In this study, holistic education was characterized by the presence of an evidence-based program; by the application of technical-metacognitive projective action; by the promotion of evolved cultural values; and by an orientation to personal consciousness evolution. The model developed has the potentiality to be a proposal of the common language needed for the diversity of holistic educational approaches.

In another study, Gallifa (2019a) defined integral thinking and characterized integral education as an actualization of the potentiality of a holistic educational approach. Four logics were found: subject-related content acquisition; evolution in learning of the knowledge shared by a group; evolution in values/culture; and orientation to personal consciousness evolution. The appropriate combination of these logics using integral thinking was defined as integral education (Gallifa 2019a). A projection of these dimensions (future trends of the necessary educational change) generated an integral education agenda: establishing a new relationship with knowledge; creating a closer relationship between education and life; paying more attention to the values of culture and organizations; and giving a greater centrality to the personal consciousness (Gallifa, 2019a). Integral education can be understood as education in these dimensions (comprehensive) and, because all of these dimensions are essential, the necessary balance between them (well-rounded).

All of these findings make more sense under the light of the presented circular-axial representation of the Integral Theory. These findings are relevant at the moment of programming emergent models of education. Emergent means models of education beyond both the modern-industrial and the postmodern models, which are the nowadays more present and influential models in practical educational contexts. 


\subsection{Four Kinds of Educational Relationships to Facilitate Human Evolution and Development}

Another potentiality of this circular-axial representation is to clarify potential educational roles and relationships. Four kinds of educator-educated relationships to facilitate human evolution and development can be characterized by the model:

Professor-student. This relationship corresponds to the objective dimension. A curiosity in this sense is that in Latin languages instead of the word "student" the common word used to name this role is "alumni". The etymology of this word is very expressive of the role: "a-lumen" means literally "without light". The light of the knowledge comes to student from outside, from the teacher-professor. This relationship points to meaningful asymmetry respect where the knowledge is.

Trainer-apprentice. This dimension is the one corresponding to the interobjective direction. It is the one that is oriented towards productive sciences. The words to name the educator role can be also "coach", "mentor" or "tutor". In any case, their job is to orient towards the acquisition of a kind of abilities, that can be physical or cognitive, technical or personal, but that is part of an expert-novice training. Metacognitive competences fall also inside this kind of abilities.

Leader-citizen. This dimension corresponds to the intersubjective evolution. The values of a culture/organization and the phronesis as a trait of ethical orientation, as well as leadership abilities, are parts of this logic. The transformative education oriented to social changes, and the style of sharing more dialogic and democratic views fall inside the logic of this educational role. Postmodern views can be easily integrated into this role.

Master-disciple. The subjective dimension of human consciousness evolution has this kind of privileged relationship. It was the common educational roles so characteristic of the premodern traditions. Here the relationship facilitates consciousness evolution and their main ingredient is the genuine and unconditional love, which is the main trait of the more evolved consciousness levels.

Concepts like "teacher" or "learning" are very general and sometimes are imprecise and not too much specific of what the purpose of a particular educational approach consists in. Many times "learning" is referred to as "learning knowledge" and "teacher" to "lecturing knowledge" to students. The more precise consciousness about the diverse roles (represented by the circular-axial model) helps in facilitating human evolution as well as the development of the corresponding lines in each dimension inside holistic and integral approaches.

\section{Conclusions}

This paper proposes a new circular-axial way to represent the Integral Theory. It's unnecessary to change any element of the theory to use this new format. Although there were presented previously small refinements in the interobjective dimension (Gallifa, 2018), they were not so big to allow the original Wilber Integral Theory to fit in the new way of representation presented.

The new circular-axial way of representation is an alternative to the representation using the quadrants. It introduces more clarification about the nature of IT, which is represented with more universal metaphysical concepts and forms. Additionally, it fits better with other representational systems. In the beginning, it may seem strange to use this new way, but because there is a more meaningful correspondence with internal and external representations, is very easy to be familiar with it, and is also easier to use. And once familiar with the new system, the representation using quadrants may seem relatively unnatural and arbitrary.

The map is not the territory, but the IT community has the responsibility to use an enhanced map to have a, as accurate as possible, knowledge of the territory. This new circular-axial representation can be proposed as this more accurate map.

The circular-axial representation highlights the appropriateness of holistic education (potentiality) and integral education (actuality) approaches.

The model allows for the clarification of the educational roles in each one of the directions of human evolution. Having these roles appropriately clarified helps in promoting and facilitating, in each case, better and more conscious ways to promote human evolution and personal development. Integral education can be understood as the actuality of educating simultaneously in the four dimensions. It needs consciousness about the diverse roles. Integral education is, in sum, an emergent model with respect to both the modern-industrial and postmodern, integrating traits of the premodern.

The development of the circular-axial representation has relevance because can be used as a framework to contextualize the humanization process resulting from the elevation of consciousness. In particular, can serve as a framework for human evolution and human developmental lines. This perspective can be valuable for 
education and it is particularly relevant for holistic or integral educational approaches. A significant consequence is the clarification of the educational roles directed to the enhancement of evolutional and developmental human potential. These conceptualizations can be starting points for future research.

\section{References}

Beck, D. E., \& Cowan, C. (2005). Spiral Dynamics: Mastering Values, Leadership, and Change. New York: Wiley/Blackwell.

Botella, L., \& Gallifa, J. (1995). A constructivist approach to the development of personal epistemic assumptions and worldviews. Journal of Constructivist Psychology, 8(1), 1-18.

Chalmers, D. J. (2018). The Meta-Problem of Consciousness. Journal of Consciousness Studies, 25(9-10), 6-61.

Esbjörn-Hargens, S. (2005). Integral Education by Design: How Integral Theory Informs Teaching, Learning, and Curriculum in a Graduate Program. ReVision, 28(3), 21-29.

Gallifa, J. (2018). The Tekhne-Logic Revolution. Rethinking the "Interobjective" Dimension of the Integral Theory. Consequences and Relevance to Education. Creative Education, 9(7), 1084-1104. https://doi.org/10.4236/ce.2018.97081

Gallifa, J. (2018b). Paradigms and Methodologies for Knowledge Building. Review of Educational Theory, 1(3), 70-81. https://doi.org/10.30564/ret.v1i3.70

Gallifa, J. (2018c). Research traditions in social sciences and their methodological rationales. Aloma, Revista de Psicologia, Ciències de l'Eduació i de l'Esport, 36(2), 9-20.

Gallifa, J. (2018d). Holonic Theory and Holistic Education. Journal of International Education and Practice, l(1), 36-46 https://doi.org/10.30564/jiep.v1i1.415

Gallifa, J. (2019a). Integral thinking and its application to integral education. Journal of International Education and Practice, 1(2).

Gallifa, J. (2019b). Transformar el Sistema Educatiu de Catalunya. Una proposta des de l'Educació Integral. Barcelona: Editorial Claret (In Press).

Gardner, H. (2003). La inteligencia reformulada: las inteligencias múltiples en el siglo XXI. Barcelona: Editorial Paidós.

Gardner, H. (2016). The theory of Multiple Intelligences. Barcelona: Universitat Ramon Llull.

Harari, Y. N. (2014). Sapiens: A Brief History of Humankind. New York: Random House.

Helfrich, P. M. (2007). Ken Wilber's model of human development. An overview. Retrieved 4 Aug 2018, from http://www.paulhelfrich.com/library/Helfrich_P_The_Five_Phases_of_Wilber.pdf

Helfrich, P. M. (2008). Ken Wilber's AQAL metatheory: An overview. Castaic, CA: Wildfire Media.

Jahn, R. G. (1989). Anomalies: Analysis and aesthetics. Journal of Scientific Exploration, 3(1), 15-26.

Koestler, A. (1967). The ghost in the machine. New York, NY: MacMillan.

Kuhn, T. S. (1970). The Structure of Scientific Revolutions (2nd enl. ed.). Chicago IL: University of Chicago Press.

Laloux, F. (2014). Reinventing Organizations: A Guide to Creating Organizations Inspired by the Next Stage of Human Consciousness. Brussels: Nelson Parker.

Murray, T. (2009) What is the Integral in Integral Education? From Progressive Pedagogy to Integral Pedagogy. Integral Review, 5(1), 1-38.

Orme-Johnson, D. W., \& Oates, R. M. (2009). A field-theoretic view of consciousness: Reply to critics. Journal of Scientific Exploration, 23(2), 139-166.

Smythies, J. (2009). Brain and Consciousness: The Ghost in the Machines. Journal of Scientific Exploration, 23(1), 37-50.

Teilhard de Chardin, P. (2002). The phenomenon of man. New York NY: Harper Collins.

Thomas, B. (2018). Integral Leadership Manifesto. Retrieved 5 Nov 2018, from http://integralleadershipmanifesto.com

Wilber, K. (1979). A developmental view of consciousness. Journal of Transpersonal Psychology, 11(1), 1-21. 
Wilber, K., Engler, J., \& Brown, D. (1986). Transformations of consciousness: conventional and contemplative perspectives on development. Boston, MA: Shambhala.

Wilber, K. (1993). Spectrum of consciousness. Wheaton, IL: Quest.

Wilber, K. (1995). Sex, ecology, and spirituality. Boston, MA: Shambhala.

Wilber, K. (1996). Up from Eden: A transpersonal view of human evolution. Wheaton, IL: Quest.

Wilber, K. (1996b). The Atman project: A transpersonal view of human development. Wheaton, IL: Quest.

Wilber, K. (1997). The eye of spirit: An integral vision for a world gone slightly mad. Boston, MA: Shambhala.

Wilber, K. (1997b). An integral theory of consciousness. Journal of consciousness studies, 4(1), 71-92.

Wilber, K. (1998). The marriage of sense and soul: Integrating science and religion. New York, NY: Random House.

Wilber, K. (2000). Waves, streams, states, and self. Further considerations for an integral theory of consciousness. Journal of Consciousness Studies, 7(11-12), 145-176.

Wilber, K. (2001). The theory of everything. Boston, MA: Shambhala.

Wilber, K. (2001b). Eye to eye: The quest for a new paradigm. Boston, MA: Shambhala.

Wilber, K. (2001c). No boundary: Eastern and western approaches to personal growth. Boston, MA: Shambhala.

Wilber, K. (2005). Introduction to Integral Theory and Practice IOS basic and the AQAL map. AQAL Journal of Integral Theory and Practice, 1(1), 1-38.

Wilber, K. (2005b). A Sociable God: Toward a new understanding of religion. Boston, MA: Shambhala.

Wilber, K. (2007). The integral vision: A very short introduction. Boston, MA: Shambhala.

\section{Copyrights}

Copyright for this article is retained by the author(s), with first publication rights granted to the journal.

This is an open-access article distributed under the terms and conditions of the Creative Commons Attribution license (http://creativecommons.org/licenses/by/4.0/). 